\title{
Pattern of Presentation of Chronic Venous Insufficiency in CVI Clinic of Chittagong Medical College Hospital
}

\author{
Md. Salim ${ }^{1 *}$ \\ GM Zakir Hossain ${ }^{2}$ \\ Mahmudur Rahman ${ }^{3}$ \\ Md.Monirul Alam ${ }^{4}$ \\ Muallem Al Farukh Khan ${ }^{5}$ \\ 'Department of Surgery \\ General Hospital \\ Rangamati, Bangladesh. \\ ${ }^{2}$ Department of Urology \\ Chittagong Medical College \\ Chittagong, Bangladesh. \\ ${ }^{3}$ Department of Orthopadic Surgery \\ Upazila Health Complex Lohagara \\ Chittagong, Bangladesh. \\ ${ }^{4}$ Department of Anaesthesiology \\ Chattagram International Medical College \\ Chittagong, Bangladesh. \\ ${ }^{5}$ Department of Urology \\ Rangamati Medical College \\ Rangamati, Bangladesh.
}

\begin{abstract}
Background: Chronic Venous Insufficiency (CVI) is a common but often ignored problem in primary health care, sign and symptoms may ranges from mild leg heaviness or aching, dilated or unsightly veins, or troublesome odema to fibroses subcutaneous panniculitis associated with recurrent cellulitis and chronic ulceration. Methods: The prospective observational study was carried out Depaertment of Surgery, Chittagong Medical College Hospital, Chittagong. The primary purpose of the present study was to evaluate the impact of the diagnostic approach on patient of chronic venous insufficiency, varicose vein to difference primary and secondary venous insufficiency. Results: Most common sign flebedema found in 56 (65.12\%) patients was followed by dermo-hypodermatitis in 15(17.44) patients, stasis eczema in 09(10.47) patients and thrombophlebitis in 06(6.98) patients. Most frequent lower leg symptoms are heaviness $82(95.35 \%) \&$ the lowest is throbbing $55(63.95 \%)$. The others are according to order of Frequency cramps 66 (70.0\%) Itching 63 (73.26\%) Burning 61(70.93\%) Tiredness 69 (80.23\%) Restless leg 71 (82.55\%) Pain aching 76 (88.37\%). CVI (Chronic Venous Insufficiency) studied $04(4.65 \%)$ were in C1, $54(62.79 \%)$ were in $\mathrm{C} 2,03(3.49 \%)$ were in $\mathrm{C} 3,11(12.79 \%)$ were in $\mathrm{C} 4,6(6.98 \%)$ were in C5 and $8(9.30 \%)$ were in C6 according to clinical CEAP classification. Conclusion: Majority of patients presented with the complains of heaviness of leg and unexplained leg swelling, sex predilection is almost same for male and female but advanced stages are more common in male patients. Increasing age is associated with more advanced stage of the disease.
\end{abstract}

Key words : Chronic Venous Insufficiency (CVI); Progressive disease; Thrombotic syndrome; Vericose veins.

\section{INTRODUCTION}

The term chronic venous insufficiency refers to the venous valvular incompetence in the superficial, deep and/or perforating veins. Incompetence of the vein valves permits reversal of flow and promotes venous hypertension in the distal segments. This form of venous dysfunction may be the result of recanalisation of thrombosed venous segments, pathological dilation of the vein or due to congenital absence of competent valves $^{1}$. Chronic Venous Insufficiency (CVI) is one of the most prevalent, frequently unrecognized and underestimated disease world wide ${ }^{2}$. It is a progressive disease $^{3}$. Chronic venous insufficiency includes all changes resulting from dilatation of veins of the lower limb, incompetence of their valves and resultant venous hypertension. presentation of CVI varies, ranging from incomplecated ankle oedema to the most severe form of post thrombotic syndrome ${ }^{4}$. 
Typical symptom of Chronic venous insufficiency includes aching pain, tightness, skin irritation, purities, heaviness, tingling, muscle cramps, cosmetically unsatisfying varicose vein. In Europe, the Prevalence of venous diseases in subjects aged 30 to 70 has been estimated at between $25 \%$ and $50 \%{ }^{5-7}$. venous leg ulcer is certainly one of the mo sever complication of CVI. Its prevalence in general population is between $0.1 \%$ and $3.2 \%{ }^{8}$. Prevalence estimates vary widely by geographic location, with the highest reported rates in Western countries. Reports of prevalence of chronic venous insufficiency vary from $<1 \%$ to $40 \%$ in females and from $<1 \%$ to $17 \%$ in males. Prevalence estimates for varicose veins are higher, $<1 \%$ to $73 \%$ in females and $2 \%$ to $56 \%$ in males ${ }^{9}$. A lower prevalence has been observed in men but some recent surveys have suggested that the occurrence in men may be comparable to that in women ${ }^{10}$. This study was designed to see various modes of presentation of chronic venous insufficiency, to find out the risk factors and to sec relationship to various symptoms of chronic venous insufficiency with age, sex and body mass index of the patient.

\section{MATERIALS AND METHODS}

This prospective cross sectional study was carried out Dept of Surgery, Chittagong Medical College Hospital (CMCH). Chittagong during July 2008 to June 2009 patients who attended in CVI clinic at Chittagnog Medical College Hospital. Patients who were aged 18 years and above and willing for treatment and given informed written consent were included this study and patients below 18 years of age were excluded in this study. Data collected with a pre-tested structured questionnaire containing history, clinical, laboratory investigations, pre-operative, post operative complications and post operative follow up findings. Data collected, compiled and tabulated according to key variables. The analysis of different variable done according to standard statistical analysis by using SPSS-19.

\section{RESULTS}

The mean age was $54.68( \pm 7.45)$ years, minimum age was 18 years and maximum age was 75 years. Among 86 patients, majority of the patients in this study was male which was $45(52.33 \%)$ rest of $41(47.67 \%)$ were female. Male female ratio 1.09: 1. Most of the patients 34(39.53\%) showed both symptoms \& sign of venous diseases for less than 5 years (Table 1). BMI of all patients were calculated and it shows that 20(44.44\%) male patients are obese and 30(73.17\%) were female patients obese (Table 2). Among 86 Patients, 56 gave history of prolonged standing. Most of the patients 36 (64.30\%) gave history of standing more than $8 \mathrm{hrs} /$ day (Table 3 ). Determinants of chronic venous insufficiency majority $48(55.81 \%)$ were varicose disease, followed by $35(40.70 \%)$ were deep thrombophlebitis, 03(3.49\%) were venous dysplasia cases (Table 4). The most frequent lower leg symptoms are heaviness $82(95.35 \%) \&$ the lowest is Throbbing 55(63.95\%). The others are according to order of Frequency cramps 66 (70.0\%), Itching $63(73.26 \%)$ Burning 61(70.93\%) Tiredness 69 (80.23\%) Restless leg 71 (82.55\%) Pain aching 76 (88.37\%) ( Table 5). Among 85 cases of CVI studied 04 (4.65\%) were in C1, $54(62.79 \%)$ were in $\mathrm{C} 2,03(3.49 \%)$ were in $\mathrm{C} 3,11(12.79 \%)$ were in $\mathrm{C} 4,6(6.98 \%)$ were in $\mathrm{C} 5$ and $8(9.30 \%)$ were in $\mathrm{C} 6$ according to clinical CEAP classification. Analysis of doppler ultrasound finding of 59 patients shows 46 patients had involvement of superficial venous system (78\%). Among than 15 patients had superficial venous incompetence $(25.42 \%) 13$ patients had perforators incompetence $(22.03 \%) \& 18$ patients had both superficial venous \& proportions incompetence (30.51\%) 13 patients had deep venous involvement among then. 11 patients had venous incontinence $(18.64 \%) 2$ patients had deep venous thrombosis (3.40\%) (Table 6).

\section{RESULTS}

Table 1 : Demographic characteristics of the study population.

\begin{tabular}{lcc}
$\begin{array}{l}\text { Demographic } \\
\text { characteristics }\end{array}$ & Number & Percentage \\
Age in years & & \\
(Mean \pm SD) & $54.68( \pm 7.45)$ & Range $18-75$ years \\
Sex & & \\
$\quad$ Male & 45 & $52.33 \%$ \\
$\quad$ Female & 41 & $47.67 \%$ \\
Time of diagnosis & & \\
by years & & \\
$\quad 0-5$ yrs & 34 & $39.53 \%$ \\
$\quad 6-10$ yrs & 28 & $32.56 \%$ \\
$\bullet>10$ yrs & 24 & $27.91 \%$ \\
\hline
\end{tabular}

Table 2 : Distribution of patients according to BMI (Body Mass Index).

$\begin{array}{lrr}\text { BMI }(\mathbf{k g} / \mathbf{m} 2) & \text { Number of Patients } & \text { Percentage } \\ \text { Male }(\mathrm{n}=45) & & \\ >25 & 20 & 44.44 \% \\ 20-25 & 24 & 53.33 \% \\ <20 & 02 & 4.17 \% \\ \text { Female }(\mathrm{n}=41) & & \\ >24 & 30 & 73.17 \% \\ 19-24 & 09 & 21.95 \% \\ <19 & 02 & 4.88 \%\end{array}$

Table 3 : Prolonged standing position.

\begin{tabular}{lcc} 
Group & Total no of patients & Percentage \\
$<4 \mathrm{Hrs} /$ Day & 06 & $10.71 \%$ \\
$4-8 \mathrm{Hrs} /$ Day & 14 & $24.99 \%$ \\
$>8 \mathrm{Hrs} /$ Day & 36 & $64.30 \%$ \\
Total & 56 & $100.00 \%$ \\
\hline
\end{tabular}


Table 4 : Determinant factors distribution.

\begin{tabular}{lcc} 
& Number & Percentage \\
Varicose disease & 48 & $55.81 \%$ \\
Deep thrombophlebitis & 35 & $40.70 \%$ \\
Venous dysplasia & 03 & $3.49 \%$ \\
Total & 86 & $100.00 \%$ \\
\hline
\end{tabular}

Table 5 : Lower leg symptoms.

\begin{tabular}{lcc} 
Symptoms & Total no of patients & Percentage \\
Pain aching & 76 & $88.37 \%$ \\
Heaviness & 82 & $95.35 \%$ \\
Swelling & 79 & $91.86 \%$ \\
Cramps & 66 & $70.00 \%$ \\
Burning & 61 & $70.93 \%$ \\
Itching & 63 & $73.26 \%$ \\
Tiredness & 69 & $80.23 \%$ \\
Restless Leg & 71 & $82.55 \%$ \\
Throbbing & 55 & $63.95 \%$ \\
Total & 86 & $100.00 \%$ \\
\hline
\end{tabular}

Table 6 : CEAP classification.

\begin{tabular}{lcc} 
CEAP Classification & Total no of patients & Percentage \\
C0 & -- & $0.00 \%$ \\
C1 & 04 & $04.65 \%$ \\
C2 & 54 & $62.79 \%$ \\
C3 & 03 & $03.49 \%$ \\
C4 & 11 & $12.79 \%$ \\
C5 & 06 & $06.98 \%$ \\
C6 & 08 & $09.30 \%$ \\
Total & 86 & $100.00 \%$ \\
\hline
\end{tabular}

Table 7 : Doppler Ultrasound findings of patients with varicose vein.

\begin{tabular}{lcc} 
Findings & No of patients & Percentage \\
Superficial venous & & \\
incompetence & 15 & $31.25 \%$ \\
Perforators Incompetence & 13 & $27.08 \%$ \\
Mixed Superficial \& & & \\
perforates in competence & 20 & $41.67 \%$ \\
Total & 48 & $100.00 \%$ \\
\hline
\end{tabular}

\section{DISCUSSION}

The venous system is one of the largest organs of the body, and venous disease is a burden for the society and a cause of much disability ${ }^{11}$. Chronic venous insufficiency may affect globally $25-50 \%$ of adult population and its costs both personal to individual and economic to society are well documented ${ }^{12-20}$.
Many contributing factors are involved in the genesis of varicose disease of the lower limbs such as age, sex, heredity, sedentary life style, number of pregnancies, overweight etc ${ }^{21}$. In present study showed the most frequent lower leg symptoms are heaviness $82(95.35 \%) \&$ the lowest is throbbing $55(63.95 \%)$. The others are according to order of Frequency cramps 66 (70.0\%), Itching (73.26\%) Burning 61(70.93\%) Tiredness $(80.23 \%)$ Restless leg $(82.55 \%)$ Pain aching 76 (88.37\%). Shahin-Ul-Islam MM et al. study showed according to presentation, $87(87 \%)$ patients have heaviness in leg, $75(75 \%)$ patients have aching pain in leg, $70(70 \%)$ have leg swelling, 68 (68\%) have cramping leg pain, 48 (48\%) have tiredness, 43 (43\%) have burning pain, 39 (39\%) have engorged leg vein, 21 (21\%) have restless leg at night, 18 (18\%) have throbbing leg pain, 13 (13\%) have itching, 7(7\%) have various skin changes including lipodermatosclerosis, eczematization, white atrophy etc and only $3(3 \%)$ patients have active leg ulcer ${ }^{22}$.

In present study showed BMI of all patients were calculated and it shows that 20(44.44\%) male patients are obese and $30(73.17 \%)$ were female patients obese. In Shahin-Ul-Islam $\mathrm{MM}$ et al study searching obesity, 63 patients $(63 \%)$ out of 100 were obese/ overweight having BMI $>25 \mathrm{~kg} / \mathrm{m}^{2}$ in case of male and $>24 \mathrm{~kg} / \mathrm{m}^{2}$ in case of female ${ }^{22}$. This finding is comparable with the study conducted at the Straub Clinic and Hospital in Hawaii, they studied 272 patients and found that $61 \%$ of patients were overweight ${ }^{23}$. Out of 63 overweight patients, 42 were female and 21 were male, this is also comparable with analysis of the Balse, the Framingham, and the Edinburgh studies, which shows association between varicose vein and obesity or overweight, is more marked in female than in male ${ }^{24-26}$.

In this study shows among 85 cases of CVI studied 04 (4.65\%) were in $\mathrm{C} 1,54(62.79 \%)$ were in $\mathrm{C} 2,03(3.49 \%)$ were in $\mathrm{C} 3$, $11(12.79 \%)$ were in $\mathrm{C} 4,6(6.98 \%)$ were in C5 and $8(9.30 \%)$ were in $\mathrm{C} 6$ according to clinical CEAP classification. In study of Shahin-Ul-Islam MM et al observed among 100 cases of CVI studied, $3(3 \%)$ were in C0, $11(11 \%)$ were in $\mathrm{C} 1,16$ $(16 \%)$ were in $\mathrm{C} 2,60(60 \%)$ were in $\mathrm{C} 3,5(5 \%)$ were in $\mathrm{C} 4,2$ (2\%) were in $\mathrm{C} 5$ and $3(3 \%)$ were in $\mathrm{C} 6$ according to clinical CEAP classification ${ }^{22}$. We know from previous description that C3 means edema of legs without skin changes. But in the community based study of Tecumseh shows $20 \%$ of subjects affected by CVI presents with leg edema ${ }^{27}$. Number of patients presented with active leg ulceration i.e C6 were $3(3 \%)$, this finding is comparable with the study conducted by Cornwall JV, Dore CJ, Lewis JD, they shows 0.1 - 3.2\% patients presented with leg ulceration ${ }^{28}$. In current study showed determinants of chronic venous insufficiency majority $48(55.81 \%)$ were varicose disease; followed by $35(40.70 \%)$ were deep thrombophlebitis 03(3.49\%) were venous dysplasia cases. Compare with Florea I et al study, they showed the determinants of chronic venous insufficiency were varicose disease 582(67.36) cases; deep thrombophlebitis 273(31.60) cases, venous dysplasia 9(1.04) cases $^{29}$. 
In this study shows ulcer location unilateral leg ulcers were $59(68.60 \%)$ cases and bilateral leg ulcers were $27(31.40 \%)$ cases. Florea I et al study showed ulcer location unilateral leg ulcers 618 cases $(71.5 \%)$; bilateral leg ulcers 246 cases $(28.5 \%)^{29}$.

In this study the contributory factors in our group of patients with chronic venous insufficiency of were diabetes mellitus $13(15.12 \%)$ cases, surgical factors $7(8.14 \%)$ cases, hypothyroidism $12(13.95 \%)$ cases, obesity $05(5.81 \%)$ case, cardiovascular disease vascular 5(5.81) cases, digestive disease $06(6.98 \%)$ cases, osteo-articulary pathology $15(17.44 \%)$ cases, genetic predisposition $02(2.33 \%)$ cases, multiple pregnancies $14(16.28 \%)$ cases, inactivity $05(5.81 \%)$ cases. Florea I, et al study showed associated diseases chronic venous insufficiency of were diabetes mellitus $129(14.93 \%)$ cases, surgical factors $68(7.87 \%)$ cases, hypothyroidism $122(14.12 \%)$ cases, obesity $51(5.90 \%)$ case, cardiovascular disease vascular 46(5.32\%) cases, digestive disease - 59(6.83\%) cases, osteo-articulary pathology $148(17.13 \%)$ cases, genetic predisposition $25(2.89 \%)$ cases, multiple pregnancies 137 (15.86\%) cases, inactivity $53(6.13 \%)$ cases In present study showed the most common sign flebedema found in 56 (65.12) patients was followed by dermo-hypodermatitis in 15(17.44) patients, stasis eczema in 09(10.47) patients and thrombophlebitis in 06(6.98) patients. Florea I, et al study showed the most common sign flebedema found in $65.74 \%$ patients was followed by dermohypodermatitis in $19.09 \%$ patients, stasis eczema in $9.49 \%$ patients and thrombophlebitis in $5.67 \%$ patients $^{29}$.

\section{CONCLUSION}

CVI (Chronic Venous Insufficiency) is not so uncommon in our country. Determinants of chronic venous insufficiency majority were varicose disease. Chronic venous insufficiency of were diabetes mellitus, surgical factors, hypothyroidism, obesity, cardiovascular disease, osteo-articulary pathology, multiple pregnancies. Most common sign were flebedema, dermohypodermatitis, stasis eczema and thrombophlebitis. The most common symptoms were cramps, Itching, burning, Tiredness, restless leg, pain aching. CVI (Chronic Venous Insufficiency) studied were in $\mathrm{C} 1, \mathrm{C} 2, \mathrm{C} 3, \mathrm{C} 4, \mathrm{C} 5$ and $\mathrm{C} 6$ according to clinical CEAP classification. Majority of patients presented with the complains of heaviness of leg and unexplained leg swelling, sex predilection is almost same for male and female but advanced stages are more common in male patients. Increasing age is associated with more advanced stage of the disease.

\section{DISCLOSURE}

All the authors declared no competing interest. 


\section{REFERENCES}

1. Zwiebel WJ. Ultrasound diagnosis of venous insufficiency .In: Zwiebel WJ. Introduction to vascular ultrasonography. 5th ed, WB saunders company. 2005; 479.

2. Burnard K. Venous Disorder, Bailey And Love Short Practice Of Sugary $25^{\text {th }}$ Edition. 2008; 54: 933.

3. Burnard K. Venous Disorder. $26^{\text {th }}$ ed. In Williams N, Bulstrode CJK, O'Connel PR. Bailey \& Love's Short Practice of Surgery. CRS Press. 2013;779-784.

4. Steven E. Zimmet Venous leg Ulcers: Modern evolution and management dermatology surgery. 1999; 25: 236-241.

5. Nelzen O. Epidemiology of venous ulcers, venous ulcers. 2007; 3: 27-41

6. Homan's J. Disease of the veins. NEJM, 1944: 231: 51-60.

7. Beigeleisen HI. An expert on veins. The new York times. 1991; 86: 05-08.

8. Shami SK, Sarin S, Cheatle TR. Venous ulcers and the superficial venous system .J Vasc Surg. 1993; 17-487.

9. Das S. Ulcers of the leg. Surgical Short cases $3^{\text {rd }}$ edition. 2007; 15:183.

10. Beebe-Dimmer JL, Pfeifer JR, Engle JS, Schottenfeld D. The epidemiology of chronic venous insufficiency and varicose veins. Ann Epidemiol. 2005; 15(3): 175-84.

11. Jhon J, Bergan. Update on Fundamental Causes and Management of Chronic Venous Insufficiency. The Journal of Vascular Disease, Angiology. 2003; 54: S1.

12. Sansilvestri-Morel P, Rupin A, Jaisson S. Synthesis of collagen is dysregulated in cultered fibroblasts derived from skin of subjects with varicose veins as it is in venous smooth muscle cells. Circulation. 2003; 106: 479-483.

13. Evans CJ, Fawkes FG, Ruckly VC. Prevalence of varicose veins and chronic venous insufficiency in men and women in the general population: Edinburgh Vein Study, J Epidemiol Community Health. 1999; 53: 149-153.

14. Nicolaides AN. Investigation of chronic venous insufficiency: A consensus statement. Circulation. 2002; 102: 26-63.

15. Agus GB, Allegra C, Arpaia G. Guideline for the diagnosis and treatment of chronic venous insufficiency. Italian Coll Phlebology, Int Angiol. 2001; 20: 1-73.

16. International Task Force: The management of chronic venous disorders of the leg: An evidence based report. Phlebology. 1999; 35-42.

17. Valencia IC, Falabella A, Kirsner RS. Chronic venous insufficiency and venous leg ulceration. J Am Acad Dermatol. 2001; 44: 401-424.

18. Van den, Oever R, Hepp B, Debbaut B. Socioeconomic impact of chronic venous insufficiency and leg ulcers. An underestimated public health problem. Int Angiol. 1998; 17: 161-167.

19. Ruckley CV. Socio-economic impact of chronic venous insufficiency and leg ulcers. Angiology. 1997; 48: 67-69.

20. De Castro Silva M. Chronic venous insufficiency of the lower limbs and its socio-economic significance. Int Angiol. 1991; 10: 152-157.

21. Marc-Antoine P. Chronic Venous Insufficiency: The Genetic Influence. 2003; 54.

22. Shahin-Ul-Islam MM, Haque MZ, Alam SMJ, Noman M, Siddiqui FM. Chronic venous insufficiency (CVI) : A study of 100 cases, J Medicine. 2008;9:20-26.

23. Danielsson G, Eklof B, Grandinentti A. The influence of obesity on chronic venous disease. J Vasc Endovasc Surg. 2002; 271-276.

24. Wildmer LK. Peripheral Venous Disorders: Prevalence and Socio-medical Importance, Bern: Hance Huber. 1978; 1-90.

25. Brand FN, Dannenberg AL, Abbott RD. The epidemiology of varicose veins- the Framingham study. Am J Prev Med. 1998; 4: 96-101.

26. Evans CJ, Fowkes FGR, Ruckley CV. Prevalence of varicose veins and chronic venous insufficiency in men and women in the general population: Edinburgh Vein Study, J Epidemiol Community Health. 1999; 53: 149-153.

27. Coon WW, Willis PW, Keller JB. Venous thromboembolism and other venous disease in the Tecumseh Community Health Study. Circulation. 1973; 4: 839-846.

28. Cornwall JV, Dore CJ, Lewis JD. Leg ulcers, epidemiology and aetiology. Br J Surg. 1986; 73: 693- 696.

29. Florea I. Stoica LE, olea I. Chronic Venous Insufficiency : Clinical Evolutional Aspects, Current Health Sciences Journal. 2011; 37(1):21-25. 